\title{
Surface Tension Investigation of Sn-Ti and Sn-Au Liquids Alloys
}

\author{
A. Rais ${ }^{1}$, A. Jouaiti ${ }^{2}$, R. Lbibb ${ }^{3}$ \\ ${ }^{1,2,3}$ Laboratoire de Développement Durable. Université Sultan Moulay Slimane, Faculté des Sciences et Techniques, B.P 523, Béni Mellal, \\ Maroc.
}

\begin{abstract}
The regular associated model has been applied to compute surface tension and surface segregation of Sn-Ti and Sn-Au liquids using Butler's equation. Application of model to Sn-Ti and Sn-Au systems allows us to explain their thermodynamics behaviours respectively by the existence of $\mathrm{SnTi}_{3}$ and $\mathrm{SnAu}$ associates in liquid. Computed surface tension is generally in disagreement with those of literature and decreases when temperature increases. Calculated surface tension curve shows an inflexion point for Sn-Ti and Sn-Au systems. These irregularities are explained by the presence of clusters in liquid. Calculation of surface composition suggests segregation of tin atoms to the surface at all bulk composition for Sn-Ti and Sn-Au.
\end{abstract}

Keywords: Alloys, regular associated model, Surface properties, thermodynamic properties

\section{Introduction}

Surface tension is one of the important surface properties of liquid alloys. It plays an important role to understand surface-related phenomena, such as interfacial adhesion and wettability between the soldering material and the substrate. Indeed, in order to produce a good wettability and strong adhesion at the substrate/solder interface, the surface tension of liquid solder must be low.

Due to the experimental difficulties, it is impossible to measure the surface tension of all materials which are being developed. For this purpose, several authors have proposed calculation methods of surface tension of liquid [1-11]. In our previous work [11], we have presented calculation method using Butler's equation [12] for the systems having a thermodynamic behaviour characterised by short-range order explained by the presence of associated atomic groups (cluster) in liquid. This method relates surface tension of liquid alloys to the thermodynamic data of the bulk phase. It is useful for systems that we can't measure this property or there are discrepancies between the experimental measurements. It also allows us to explain the irregularities observed in surface tension isotherms and to predict its variation with temperature.

In the present work, $\mathrm{Sn}-\mathrm{Ti}$ and $\mathrm{Sn}-\mathrm{Au}$ liquids are the alloys of interest. Our concern in these liquid alloys stems from the fact that they could be used in soldering processes in the field of advanced microelectronics and semiconductor packaging. Sn-Ti alloys are suitable materials for brazing metals to ceramics. The intrinsic ductility of the alloys should minimise the residual stress at the interface of join [13]. Sn-Au alloys are used as materials for lead-free solders [14] and have been found useful in flip-chip technology [15]. Surface tension of $\mathrm{Sn}-\mathrm{Au}$ liquid alloys has been measured by many authors [16-20] at different temperatures. There is disagreement between different authors, especially concerning the existence of irregularities in surface tension isotherms. The presence of highly reactive trace impurities, such as oxygen, in the surrounding atmosphere affects the measure of surface tension of tin based alloys; that explains the discrepancies in literature data. To our Knowledge, there are no experimental data of surface tension of Sn-Ti liquid alloys. However, Novakovic et al. [21] have calculated this property at $1423 \mathrm{~K}$ using quasi chemical approximation for regular solution.

In order to review those literature data, we calculated the surface tension of $\mathrm{Sn}-\mathrm{Ti}$ and $\mathrm{Sn}-\mathrm{Au}$ liquids alloys versus composition and temperature from thermodynamics properties of bulk phase using Butler's equation. There are few studies of thermodynamics properties of $\mathrm{Sn}$-Ti liquid alloys. They have been determined by Esin at al.[22], Nikolaenko et al.[23] and Ansara et al.[24]. The values of enthalpy of formation, $\mathrm{H}^{\mathrm{f}}$, and excess free enthalpy, $\mathrm{G}^{\mathrm{xs}}$, selected for this work are those adopted by SGTE [25] which are taken from Ref. [24]. Sn-Au system has been studied by many authors. The enthalpy of formation of liquid has been determined by Rakotomavo et al. [26,27] at $1373 \mathrm{~K}$ and 1369 and by Hayer et al. [28] at $1369 \mathrm{~K}$. The free enthalpy of formation is measured by Chevalier et al. [29]; it is in good agreement with those of Hultgren et al. [30]. The thermodynamics behaviours of studied systems are characterised by very strong negative departure to ideality, suggesting strong short-range order explained by the presence of associated atomic groups (cluster) in liquid. The regular associated model developed elsewhere [31-37] can be applied to explain the thermodynamics behaviours of these systems.

The aim of this work is the application of regular associated model to Sn-Ti and Sn-Au liquids alloys to compute surface tension and surface segregation versus temperature and composition using Butler's equation.

\section{Butler's Equation in Regular Associated Model}

The Butler's equation has been established [12] assuming an equilibrium between a bulk phase and a surface which is regarded as hypothetical phase. Its expression for liquid binary alloys is as follows: 


\section{International Journal of Science and Research (IJSR) \\ ISSN (Online): 2319-7064}

Index Copernicus Value (2013): 6.14 | Impact Factor (2014): 5.611

$$
\begin{aligned}
\sigma & =\sigma_{A}+\frac{R T}{\alpha_{A}} \ln \frac{x_{A}^{s}}{x_{A}^{b}}+\frac{1}{\alpha_{A}}\left(\bar{G}_{A}^{E, s}\left(T, x_{A}^{s}\right)-\bar{G}_{A}^{E, b}\left(T, x_{A}^{b}\right)\right) \\
& =\sigma_{B}+\frac{R T}{\alpha_{B}} \ln \frac{x_{B}^{s}}{x_{B}^{b}}+\frac{1}{\alpha_{B}}\left(\bar{G}_{B}^{E, s}\left(T, x_{A}^{s}\right)-\bar{G}_{B}^{E, b}\left(T, x_{A}^{b}\right)\right)
\end{aligned}
$$

where $R$ is the gas constant, $T$ the temperature, $\sigma_{i}$ the surface tension of pure liquid $i$ and $\alpha_{i}$ the molar surface area in monolayer of pure liquid $i$ ( $i=\mathrm{A}$ or $\mathrm{B}) . \alpha_{i}$ is obtained as $\alpha_{i}=L N_{o}^{1 / 3} V_{i}^{2 / 3}$, where $N_{\mathrm{o}}$ is the Avogadro's number, $V_{i}$ the molar volume of pure liquid $i$ and $L$ the correction factor resulting from the surface structure. The value of $L$ is usually set to be 1.091 for liquid metals assuming closed packed structure [38].

$\bar{G}_{i}^{E, s}\left(T, x_{A}^{s}\right)$ and $\bar{G}_{i}^{E, b}\left(T, x_{A}^{b}\right)$ are the partials excess free enthalpies of component $i$ versus temperature $T$ and composition $x_{A}^{s}$ and $x_{A}^{b}$ in surface and bulk phases respectively. Their expressions are deduced from free enthalpy expressed in regular associated model [11].

In associated model the mixture $\mathrm{A}-\mathrm{B}$ consists of three species, the "free" atoms $\mathrm{A}$ and $\mathrm{B}$ and the cluster $\mathrm{A}_{m} \mathrm{~B}_{n}=\mathrm{C}$ ( $m$ and $n$ are small integers). The expression of the molar free enthalpy is given by:

$$
\begin{aligned}
& G_{b}^{f}\left(x_{A}^{b}, T\right)=N_{C}^{b} z^{b} \Delta H^{\circ}+N_{T}^{b} z^{b}\left(\omega_{A B} X_{A}^{b} X_{B}^{b}\right. \\
& \left.+\omega_{A C} X_{A}^{b} X_{C}^{b}+\omega_{B C} X_{B}^{b} X_{C}^{b}\right)-T N_{C}^{b} \Delta S^{\circ}-T S_{b}^{c o n f}
\end{aligned}
$$

where $z^{\mathrm{b}}$ is the coordination number of bulk phase, and $N_{C}^{b}, X_{i}^{b}$ and $N_{T}^{b}$ are respectively the number of cluster, the molar fraction of species $i$ and the total number of species in bulk ternary system. $\Delta H^{\circ}, \Delta S^{\circ}$ and $S_{b}^{\text {cont }}$ are respectively the enthalpy and the entropy of formation of cluster, $S_{b}^{\text {conf }}$ is the molar configurational entropy and $\omega_{i j}$ are the binary interaction parameters.

The superscript and subscript $b$ refer to the quantities at the bulk phases.

Free enthalpy in the surface phase has the same expression as equation (2) by replacing superscript and subscript $b$ by $s$. We assume that $\Delta H^{\circ}, \Delta S^{\circ}$ and interaction parameters $\omega_{i j}$ are constant in the surface and bulk phases. The expression of Butler's equation in associated model is obtained by substituting the expressions of partials excess free enthalpies of components expressed in regular associated model in equation (1).

\section{Calculation of Surface Tension}

Using the enthalpy of formation and excess free enthalpy of studied liquid alloys in the whole range of composition, we can apply the regular associated model in order to elucidate the nature and the stability of clusters and to determine the binary interaction parameters $\omega_{i j}$ for each system. Usually, the compound with the highest melting temperature persists in liquid phase, and the short-range order can be explained by the presence of cluster that has the same stoichiometry.
Once given the parameters $\Delta H^{\circ}, \Delta S^{\circ}$ and $\omega_{i j}$, we calculate, versus composition, the partials free enthalpies of components in surface and bulk phases at the chosen temperature. Then, the two equations on the right-hand side of Eq. (1) become an equation with unknown $x_{A}^{s}$. This equation is solved for $x_{A}^{s}$ and the value of $x_{A}^{s}$ is substituted in Eq. (1) to calculate surface tension $\sigma$ of liquid alloy. The coordination number in the surface is taken as that for closed packed structures $\left(z^{s} / z^{b}=9 / 12\right)$. The prediction of surface tension of liquid requires knowledge of those of the pure metals. Surface tension data of pure Sn, Au and Ti are taken from [39], [20] and [40] respectively.

\section{1- Sn-Ti}

The highest melting temperature of $\mathrm{SnTi}_{3}$ compound and the location of thermodynamic function minimum near $\mathrm{x}_{\mathrm{Ti}}=0.75$ suggest that $\mathrm{SnTi}_{3}$ cluster plays an important role in the short-range order in liquid. Calculation was carried out with three interaction parameters: $\omega_{T i, S n}=-6.06 \mathrm{~kJ} / \mathrm{mol}$, $\omega_{T i, T i_{3} S n}=-8.49 \mathrm{~kJ} / \mathrm{mol}, \quad \omega_{S n, T i_{3} S n}=-14.01 \mathrm{~kJ} / \mathrm{mol} . \quad$ The enthalpy and the entropy of formation of cluster are respectively:

$\Delta H^{\circ}=-1.88 \mathrm{~kJ} / \mathrm{mol}, \Delta S^{\circ}=17.87 \mathrm{~J} / \mathrm{Kmol}$. As shown in figure 1, the assumption of $\mathrm{SnTi}_{3}$ cluster in the melt reproduces correctly the thermodynamics functions of the liquid. The compositions of different species in pseudoternary system are illustrated in figure 2 .

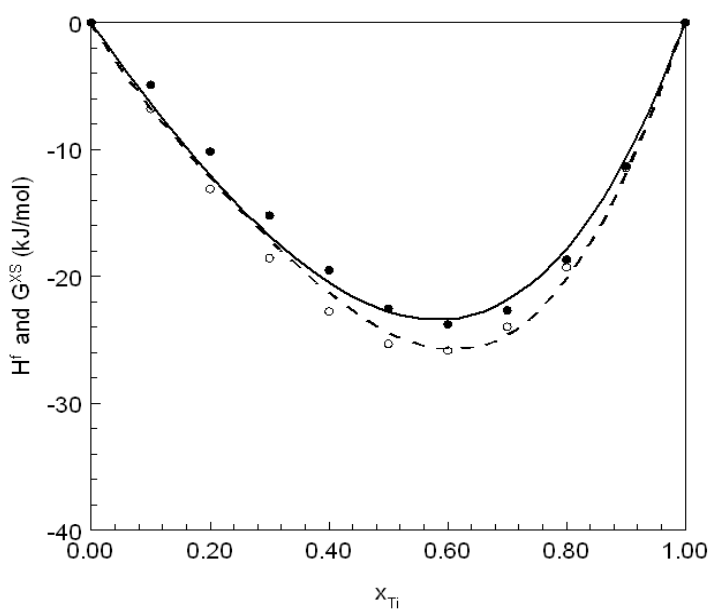

Figure 1: Enthalpy and excess free enthalpy of formation of Sn-Ti liquid at $\mathrm{T}=2000 \mathrm{~K}$.

$\mathrm{h}^{\mathrm{f}}: \quad(\bullet)$ literature [25]; (-) calculated

$\mathrm{G}^{\mathrm{XS}}$ : (o) literature [25]; (---) calculated 


\section{International Journal of Science and Research (IJSR) ISSN (Online): 2319-7064}

Index Copernicus Value (2013): 6.14 | Impact Factor (2014): 5.611

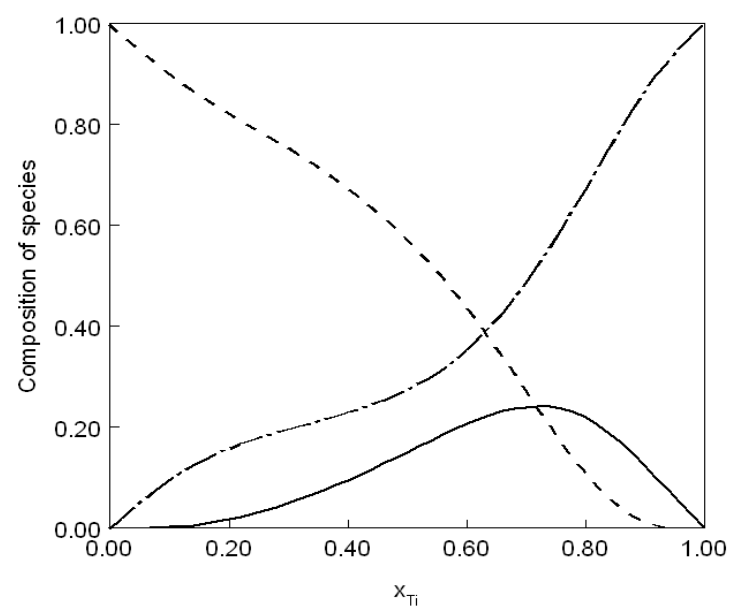

Figure 2: Composition of species of $\mathrm{Sn}$-Ti liquid at $\mathrm{T}=$ $2000 \mathrm{~K}$.

(--) free $\mathrm{Sn},(---)$ free $\mathrm{Ti},(-)$ Cluster $\mathrm{SnTi}_{3}$

The computed surface tension of Sn-Ti liquid at $1423 \mathrm{~K}$ is plotted against bulk composition in figure 3 and consigned in table 1. It is not in good agreement with that calculated by Novakovic et al. [21]. This disagreement is explained by the fact that Novakovic used quasi chemical approximation for regular solution not adapted for systems characterized by very strong negative departures to ideality. Surface tension curve presents an irregularity (inflection point) near the composition corresponding to the stoichiometry of cluster $\left(\mathrm{x}_{\mathrm{P}}=0.75\right)$. This irregularity could be explained by the presence of associates in liquid (The number of clusters is maximal at $\mathrm{x}_{\mathrm{P}_{\mathrm{t}}}=0.75$ ). According to Trifinov and Aleksandrov [41,42], the presence of inflection point in surface tension curve means that the clusters are surface active relative to only one of the alloys constituents. We have calculated $\sigma$ for this system at two other temperatures (2000 and 3000K). As shown in figure 4, the surface tension of liquid alloys Sn-Ti decreases with increasing temperature. The irregularity tends to disappear at high temperature. This is due to the dissociation of clusters by thermal agitation.

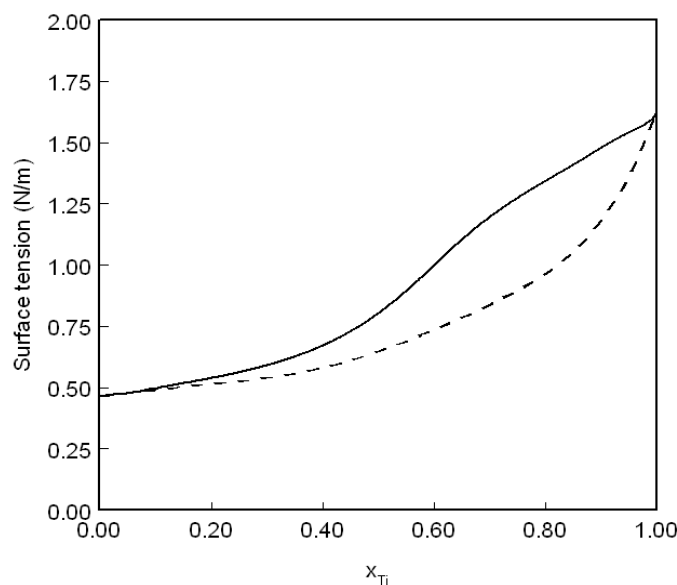

Figure 3: Surface tension of Sn-Ti liquid at 1423 K. (-) calculated, (----) literature [21]

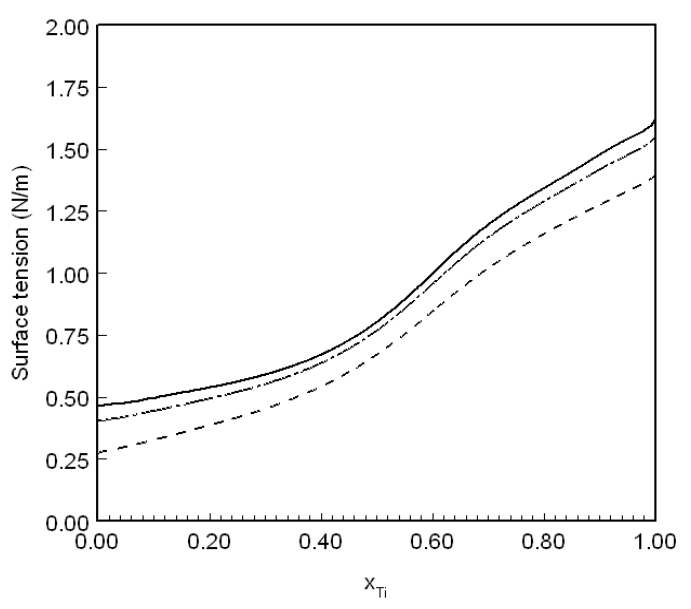

Figure 4: Surface tension of Sn-Ti liquid at different temperatures.

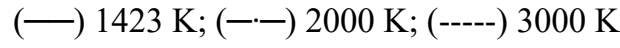

Table 1:Calculated surface tension and surface composition of $\mathrm{Sn}-\mathrm{Ti}$ and $\mathrm{Sn}-\mathrm{Au}$

\begin{tabular}{|c|c|c|c|c|}
\hline & \multicolumn{2}{|c|}{$S n-T i(1423 K)$} & \multicolumn{2}{c|}{$A u-S n(1373 K)$} \\
\hline$x_{S n}^{b}$ & $\sigma_{\text {calc }}(\mathrm{N} / \mathrm{m})$ & $x_{T i}^{s}$ & $\sigma_{\text {calc }}(\mathrm{N} / \mathrm{m})$ & $x_{S n}^{s}$ \\
\hline 0 & 1.62 & 1 & 1.132 & 0 \\
\hline 0.1 & 1.48 & 0.786 & 1.021 & 0.265 \\
\hline 0.2 & 1.34 & 0.637 & 0.954 & 0.372 \\
\hline 0.3 & 1.19 & 0.459 & 0.885 & 0.485 \\
\hline 0.4 & 0.99 & 0.197 & 0.800 & 0.643 \\
\hline 0.5 & 0.80 & 0.067 & 0.707 & 0.803 \\
\hline 0.6 & 0.67 & 0.025 & 0.630 & 0.903 \\
\hline 0.7 & 0.59 & 0.010 & 0.571 & 0.956 \\
\hline 0.8 & 0.54 & 0.004 & 0.527 & 0.982 \\
\hline 0.9 & 0.50 & 0.001 & 0.494 & 0.994 \\
\hline 1 & 0.46 & 0 & 0.472 & 1 \\
\hline
\end{tabular}

The surface composition of $\mathrm{Ti}$ at $1423 \mathrm{~K}, x_{T i}^{s}$, has been plotted, versus the bulk composition, in figure 5 and consigned in table 1. Our investigation suggests the segregation of $\mathrm{Sn}$ atoms to the surface at all bulk composition explained by the fact that there is more titanium atoms in clusters than tin atoms. Indeed, when the temperature increases, the clusters dissociate and the number of free titanium increases more than free tin, hence more atoms of titanium can segregate to the surface (figure 5). As shown in figure 5, the segregation of tin decreases when temperature increases. The segregation of tin at the surface plays an important role in interfacial adhesion because $\mathrm{Sn}$ strongly reacts with most metals and forms a stable intermetallic bond at the interface solder/substrate. 


\section{International Journal of Science and Research (IJSR) \\ ISSN (Online): 2319-7064}

Index Copernicus Value (2013): 6.14 | Impact Factor (2014): 5.611

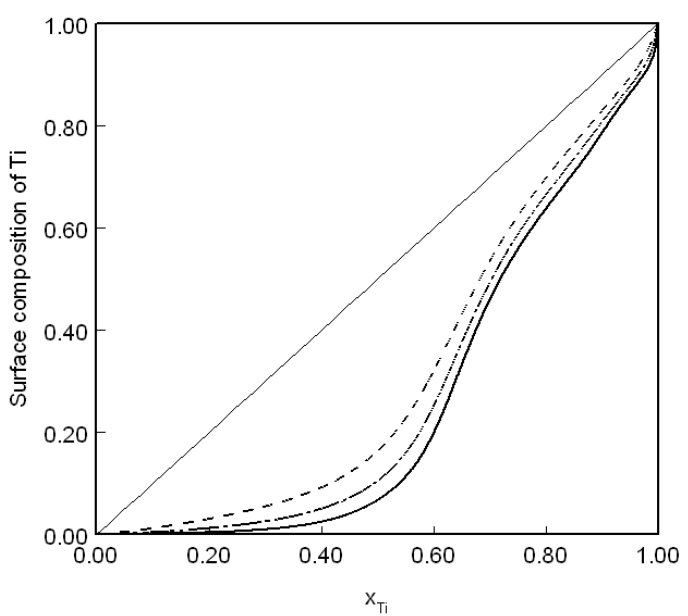

Figure 5: Surface composition of Ti at different temperatures.

(一) $1423 \mathrm{~K} ;(--$ ) $2000 \mathrm{~K} ;(----) 3000 \mathrm{~K}$

\section{2- Sn-Au}

The fact that the minimum of enthalpy of formation and excess free enthalpy of $\mathrm{Sn}$-Au liquid alloys lies very close to $\mathrm{x}_{\mathrm{Au}}=0.5$ and the highest melting temperature of $\mathrm{SnAu}$ compound suggests that the thermodynamic behaviour of $\mathrm{Sn}-\mathrm{Au}$ liquid alloys could be explained by the presence of $\mathrm{SnAu}$ clusters in liquid. The calculation was carried out with two interaction parameters: $\omega_{S n, S n A u}=-0.2 \mathrm{~kJ} / \mathrm{mol}$, $\omega_{A u, S n A u}=-2.09 \mathrm{~kJ} / \mathrm{mol}$. The enthalpy and the entropy of formation of cluster are respectively: $\Delta H^{\circ}=-1.93 \mathrm{~kJ} / \mathrm{mol}, \Delta S^{\circ}=8.7 \mathrm{~J} / \mathrm{Kmol}$. As shown in figure 6 , there is a good agreement between measured and calculated values of enthalpy of formation and excess free enthalpy. At the stoichiometry of associates the melt is strongly associated $\left(X_{S n A u}=0.59\right)$ (figure 7).

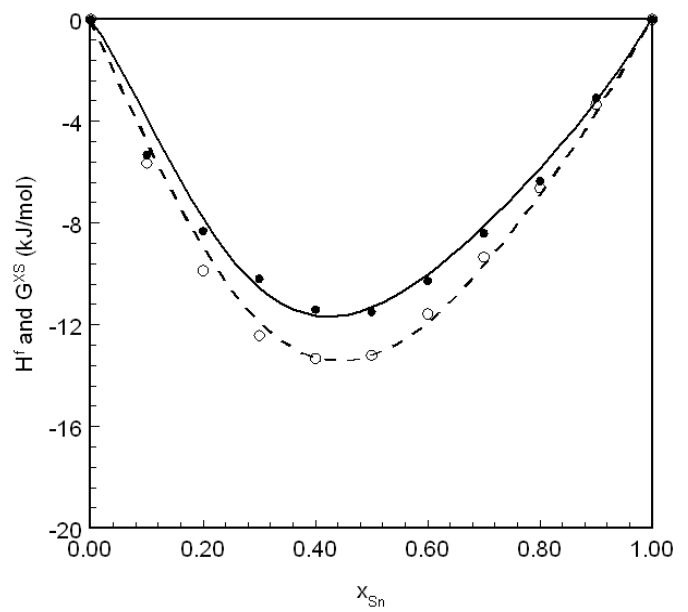

Figure 6: Enthalpy and excess free enthalpy of formation of $\mathrm{Sn}-\mathrm{Au}$ liquid at $\mathrm{T}=1373 \mathrm{~K}$.

$\mathrm{h}^{\mathrm{f}}$ : (•) literature [26]; (-) calculated

$\mathrm{G}^{\mathrm{XS}}$ : (o) literature [29]; (---) calculated

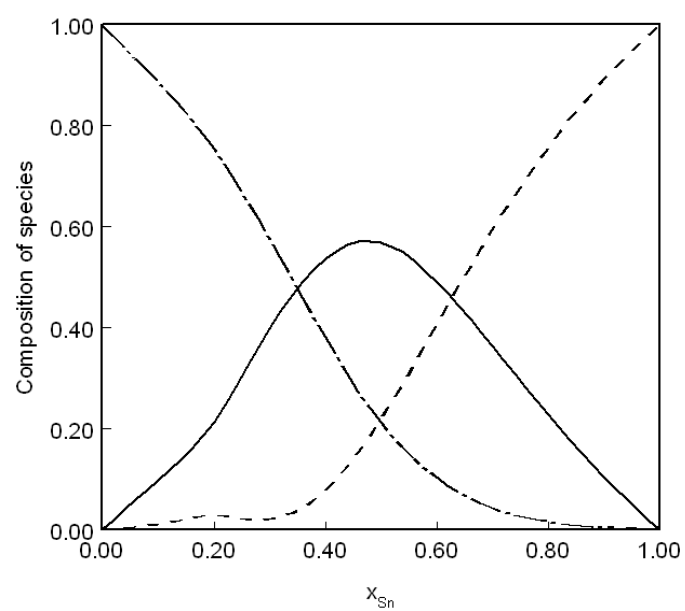

Figure 7: Composition of species of $\mathrm{Sn}-\mathrm{Au}$ liquid at $\mathrm{T}=$ $1373 \mathrm{~K}$.

(---) free $\mathrm{Sn},(---)$ free $\mathrm{Au},(-)$ Cluster $\mathrm{SnAu}$

Surface tension has been calculated at $\mathrm{T}=1373 \mathrm{~K}$. It is consigned in table 1 and plotted against the bulk composition with experimental data in figure 8. As can be seen in figure, the calculated surface tension for $\mathrm{x}_{\mathrm{Sn}}>0.5$ shows a better agreement with those of Novakovic et al. [20]. When compared with sutface tension literature data, a general agreement among data is poor. The effect of oxidation of tin based liquid alloy seems to have a strong influence on measurement of its surface tension; that explains the discrepancies in literature data and makes it difficult the comparison between the measured and computed values.

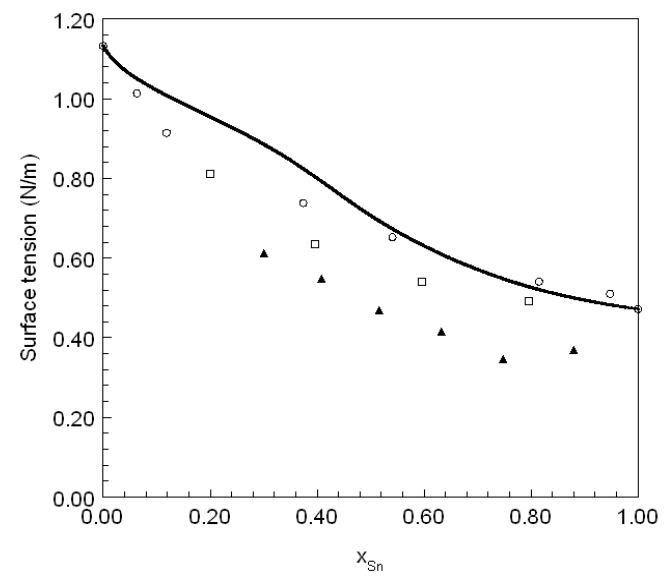

Figure 8: Surface tension of $\mathrm{Sn}-\mathrm{Au}$ liquid at $\mathrm{T}=1373 \mathrm{~K}$ $(-)$ calculated, (o) Novakovic [20], (ロ) Khilya [18], ( $\mathbf{\Delta})$ Kaufman [19] 


\section{International Journal of Science and Research (IJSR) \\ ISSN (Online): 2319-7064}

Index Copernicus Value (2013): 6.14 | Impact Factor (2014): 5.611

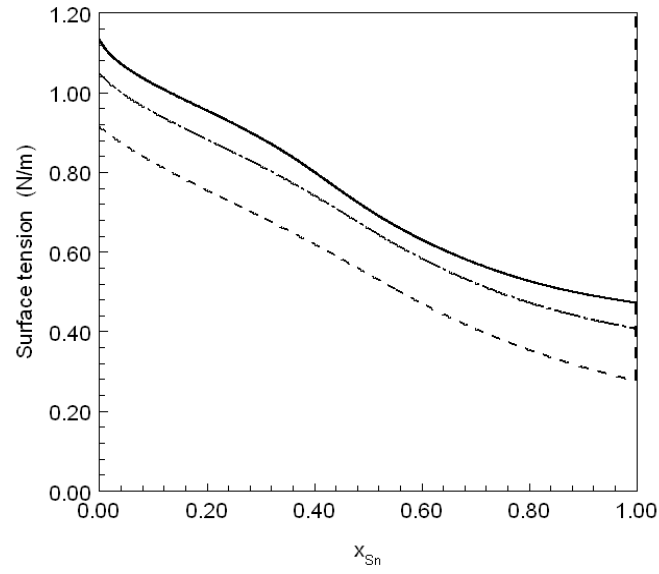

Figure 9: Surface tension of Sn-Au liquid at different temperatures

(一) $1373 \mathrm{~K} ;($ (--) $1600 \mathrm{~K} ;(----) 2000 \mathrm{~K}$

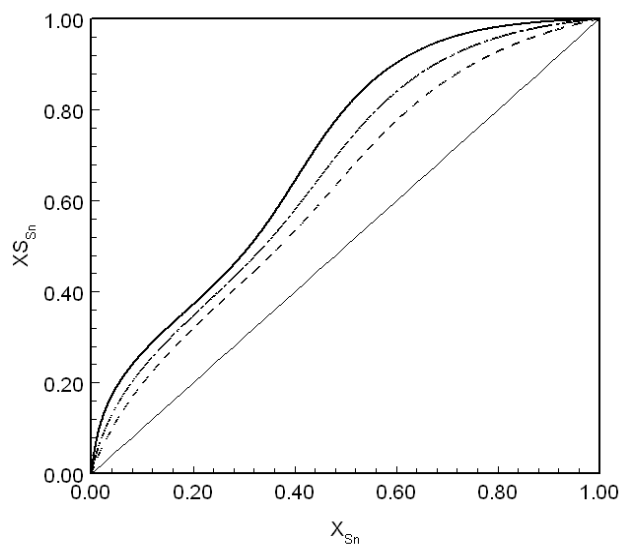

Figure 10: Surface composition of $\mathrm{Sn}$ at different temperatures.

(-) $1373 \mathrm{~K} ;(---) 2000 \mathrm{~K}$; (-----) $3000 \mathrm{~K}$

Computed surface tension curve presents near the composition corresponding to the stoichiometry of cluster $\left(\mathrm{x}_{\mathrm{Sn}}=0.5\right)$ an irregularity (inflection point), which disappears at high temperature (figure 9) explained by the presence of clusters and their dissociation by thermal agitation. As Sn-Ti liquid, the surface tension of $\mathrm{Sn}-\mathrm{Au}$ decreases with increasing temperature. Calculation of surface composition shows that tin segregates to the surface at all bulk composition (figure 10 and table 1) which could be explained by the importance of the interaction between gold and cluster $\left(\omega_{A u, S n A u}=-2.09 \mathrm{~kJ} / \mathrm{mol}\right)$ compared to that of tin and cluster $\left(\omega_{S n, S n A u}=-0.2 \mathrm{~kJ} / \mathrm{mol}\right)$. Within the bulk composition range of $\mathrm{x}_{\mathrm{Sn}}=0.2$ and 0.3 the segregation of tin decreases because the slope of the curve of variation of number of clusters increases in this range of composition (figure 7) and many atoms of tin are engaged in clusters. Because of dissociation of clusters the segregation of tin decreases when temperature increases (figure 10).

\section{Conclusion}

Thermodynamics behaviors of Sn-Ti and Sn-Au liquids have been explained respectively by the presence of $\mathrm{Ti}_{3} \mathrm{Sn}$ and $\mathrm{SnAu}$ clusters. Near the composition corresponding to clusters stoichiometries, calculated surface tension of $\mathrm{Sn}-\mathrm{Ti}$ and $\mathrm{Sn}-\mathrm{Au}$ liquid presents an inflexion point which disappears at high temperature, explained by the presence of clusters in liquid. The surface tension decreases when temperature increases due to dissociation of clusters by thermal agitation. Calculation of surface composition shows segregation of tin at all bulk composition for $\mathrm{Sn}-\mathrm{Ti}$ and $\mathrm{Sn}-$ $\mathrm{Au}$ systems. The segregation of tin atoms decreases when temperature increases.

\section{References}

[1] L.C. Prassad, R.N. Singh, Phys. Rev, 24, pp.13768, 1991.

[2] L.C. Prassad, A. Mikula, J. Alloys Comp, 282, pp. 279, 1999.

[3] N. Jha, A.K. Mishra, J. Alloys Comp, 329, pp. 224, 2001.

[4] O. Akinlade, R.N. Singh, J. Alloys Comp, 33, pp.84, 2002.

[5] L.C. Prassad, A. Mikula, J. Alloys Comp, 314, pp. 193, 2001.

[6] T. Tanaka, K. Hack, T. Lida, S. Hara, Z. Metallkd, 87, pp.380,1996).

[7] T.P. Hoar, D.A. Melford, Trans. Faraday Soc, 53, pp. 315, 1957.

[8] K.S. Yeum, R. Speiser, D.R. Poirier, Metall. Trans, B 20, pp.693, 1989.

[9] H.K. Lee, J.P. Hajra, M.G. Frohberg, Z. Metallkd, 83, pp. 8, 1992.

[10] M. Roesner-Kuhn, G. Kuppermann, U. Thiedemann, K. Drewes, T. Schmidt-Lehmann, M.G. Frohberg, Ber. Bunsenges. Phys. Chem, 102, pp. 1163, 1989.

[11]A. Rais, R. Lbibb, J. Alloys and compounds, 381, pp. 197, 2004.

[12] J.A.V. Butler, Proc. R. Soc. Lond. Ser. A, 135, pp. 348, 1932.

[13] R. Kapoor, T. W. Eagar, Metall. Trans, 20B, pp. 919, 1989.

[14] J.H. Lau, Van Nostrand Reinhold, New York, 1991.

[15]H.K. Jong, W.J. Sang, M.L. Hyuck, J. Electron. Mater, 31(6), pp. 557, 2002.

[16]B.B. Alchagirov, Kh.B. Khokonov, Fiz. Poverkh. Yavlen. Rasp. Grozny,4(2), pp. 51, 1977.

[17] N.L. Pokrovskii, P.P. Pugachevich, Kh.I. Ibragimov, Soviet Physics-Doklady, 12(2), pp. 170, 1967.

[18] G.P. Khilya, Yu.N. Ivashchenko, V.N. Eremenko, Russ. Metall, 6, pp. 72, 1975.

[19] S.M. Kaufman, T.J. Whalen, Acta Metall, 13, pp. 797, 1965).

[20]R. Novakovic, E. Ricci, F. Gnecco, D. Giuranno, Borzone, Surface Science, 599, pp. 230, 2005.

[21] R. Novakovic, E. Ricci, S. Amore and T. Lanata, Rare Metals, 25(5), pp. 457, 2006.

[22] Yu. O. Esin, M. G. Valishev, A.F. Ermakov, P.V. Geld and M.S. Petrushevskii, Zh. Fiz. Khim, 55, pp. 747, 1981.

[23] I.V. Nikolaenko, G.I. Batalin and E.A. Beloborodova, Teplofiz. Vysok. Temp, 24, pp. 690, 1986.

[24]I. Ansara, A.T. Dinsdale and M.H. Rand, COST 507, Vol. 2, EUR 18499, pp. 284, 1998.

[25]P. Franke, D. Neuschütz and Scientific Group Thermodata Europe (SGTE), Landolt-Börnstein - Group IV Physical Chemistry, V19B4, Binary Systems. Part 4. 


\section{International Journal of Science and Research (IJSR) \\ ISSN (Online): 2319-7064}

Index Copernicus Value (2013): 6.14 | Impact Factor (2014): 5.611

[26] J. Rakotomavo, Thèse de spécialité, Université de Provence, Marseille, 1979.

[27] J. Rakotomavo, M. Gaune-Escard, J.P. Bros, P. Gaune, Ber. Buns. Phys. Chem, 88, pp. 663, 1984.

[28] E. Hayer, K.L. Komarek, J.P. Bros, Gaune-Escard, Z. Metallkd, 72(2), pp. 109, 1981.

[29] P.Y. Chevalier, Thermochim. Acta, 130, pp. 1, 1988).

[30] R. Hultgren, P.D. Desai, D.T. Hawkins, M. Gleiser, K.K. Kelly, selected values of thermodynamics properties of Binary alloys, ASM International, Metals Park, OH, 1973.

[31] A.B. Bhatia, W.H. Hargrove, Phys. Rev. B 8-10, pp. 3186, 1974.

[32]F. Sommer, Z. Metallkd, 73, pp. 72, 1982.

[33]F. Sommer, Z. Metallkd, 73, pp. 77, 1982.

[34] C. Bergman, R. Castanet, H. Sa“1d, M. Gilbert, J.C. Mathieu, J. Less-Common Met, 85, pp.121, 1982.

[35] R. Castanet, M. Gilbert, J.C. Mathieu, J. Less-Common Met, 96, pp. 1, 1984.

[36]H. Saïd, R. Castanet, M. Gilbert, J.C. Mathieu, J. LessCommon Met, 96, pp. 79, 1984.

[37] R. Lbibb, M. Gilbert, R. Castanet, J. of Alloys and Compounds, 205, pp. 253, 1994.

[38] T. Tanaka, T. Iida, Steel Res, 65, pp. 21, 1994.

[39]B.J. Keene, NPL Report DMM(A)39, November 1991.

[40]P.-F. Paradis, 1, 2 T. Ishikawa, 1 and $\mathrm{S}$. Yoda, International Journal of Thermophysics, 23(3), pp. 825, 2002.

[41]N.A. Trifinov, G.K. Aleksandrov, Iz. Sektora. Fiz. Khim. Anal, 12, pp. 85, 1940.

[42] N.A. Trifinov, Iz. Sektora. Fiz. Khim. Anal, 12, pp. 103, 1940. 